\title{
THE INFLUENCE OF A REINFORCED BEAM ON THE SAFETY OF ENGINEERING STRUCTURES
}

\author{
doi: 10.2478/czoto-2021-0024
}

Date of submission of the article to the Editor: 04/12/2020

Date of acceptance of the article by the Editor: 02/04/2021

\author{
Tomasz Kwiatkowski ${ }^{1}$ - orcid id: 0000-0001-6174-823X \\ Dariusz Kwiatkowski ${ }^{1}$ \\ ${ }^{1}$ Czestochowa University of Technology, Poland
}

\begin{abstract}
The Reinforcement with carbon tapes is the next step to increase the safety of using elements of engineering structures. The conducted tests illustrate the strength capabilities of aluminum beams reinforced with a CFRP tape. The aim of the conducted tests is to compare the bending strength of aluminum beams before and after the reinforcement. On the basis of the numerical analysis, the displacements and stresses in the modeled beams were also compared. Moreover, the possible applications of the reinforced aluminum beam in engineering structures are presented in this article
\end{abstract}

Keywords: aluminum, epoxy glue, carbon tapes

\section{INTRODUCTION}

Safety has always been the basic criterion for the design, implementation and operation of engineering structures. In the past, the erection and construction of different facilities and buildings that meet this condition was most often associated with multiple attempts performed in a normal scale. The knowledge obtained in this way was passed orally among the designers. It was only after the foundations of the strength of materials that the design was developed and changed. It became possible to create theoretical models and theoretically verify the way the structure (its elements) worked before the actual creation. This period contributed to the question of the safety of the structure. Engineers realized that there are many factors that ultimately affect the behavior of an engineering object. The heterogeneity of materials was noticed and the related scatter of their mechanical parameters, randomness of interactions, manufacturing tolerances or difficulties in unambiguous mapping of the work of the structure using its model. Therefore, many considerations appeared on how to relate the results of theoretical analyzes to the actual behavior of the structure. In this way, many design methods were created and allowed to take into account the influence of various factors on the final shape of the structure. Today, the most commonly used method for the analysis of engineering structures is the finite element method. Modern computer applications allow a very precise analysis of the work of virtually any object, regardless of its degree of complexity. However, in such analyzes, it must be remembered that the computer applications are not able to fully reflect reality. Each created computer model, 
regardless of its complexity level, is only a better or worse attempt to idealize the work of an element or structure, and the results obtained on its basis are influenced by many factors (including boundary conditions or the method of its solution). What is more, thenumerical programs and the use of models in them are always only a tool in the hands of a designer who not only takes all decisions at every stage of design but also takes full responsibility for the final result of his work (Bednarski et al., 2015).

\section{THE EXPERIMENTAL PART AND RESEARCH OVERVIEW}

The research used aluminum profiles made of 6063 - T6 alloy and CFRP tapes by S\&P Lamelle CFK 150/2000, which are available on the market. ARALDIT 2014-1 glue was used to bond the aluminum beams. This glue is a two-part epoxy adhesives. The bending tests were carried out in accordance with PN-EN ISO 7438. Beams with dimensions of $50 \times 30 \times 3$ and $900 \mathrm{~mm}$ in length were subjected to a bending test according to Figure 1 (the beams, where CFRP tapes were supposed to be glued, before the process of sticking the tapes to them, were sandblasted on the surface and then cleaned with acetone). The deflection and displacement were measured in the tested beams. The reinforced beams were compared to the unreinforced beams.

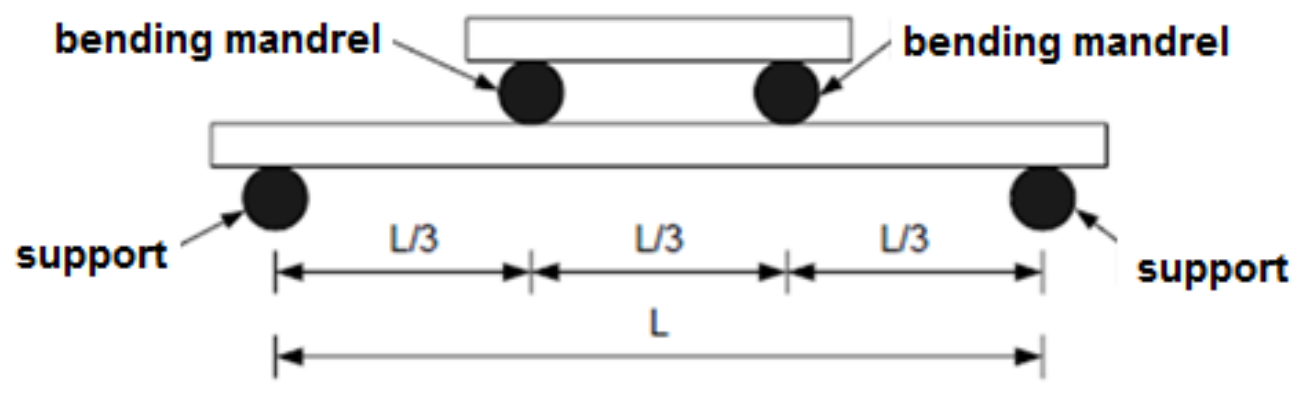

Fig. 1. The scheme of the support of bent beams, $L=750 \mathrm{~mm}$

During the first stage, the adhesion of ARALDIT 2014-1 was analyzed. The bending test was carried out up to the deflection value for which the beam failed. Fig. 2 shows the dependence of the force on displacement for a beam reinforced with a tape and an unreinforced beam. The results of bending tests in the force-displacement axis system are presented in the figures below. The use of one reinforcing tape resulted in an increase in the beam's load capacity, which was reflected in its lower displacement (deflection) for a given force level, e.g. for a high bending force of $16 \mathrm{kN}$, the deflection of the reinforced beam was about $9.2 \mathrm{~mm}$ and the beams without reinforcement about $14 \mathrm{~mm}$ (Fig. 2), which reduces the deflection by about 35\%. In each of the beams, deformation (deflection) of the side walls of the profile Fig. 3 could be observed, which partially affected its load capacity. It was also observed that the glued joint used to bond the aluminum profile to the carbon tape did not deteriorate in either the adhesive or the cohesive one, as shown in Figure 3. 


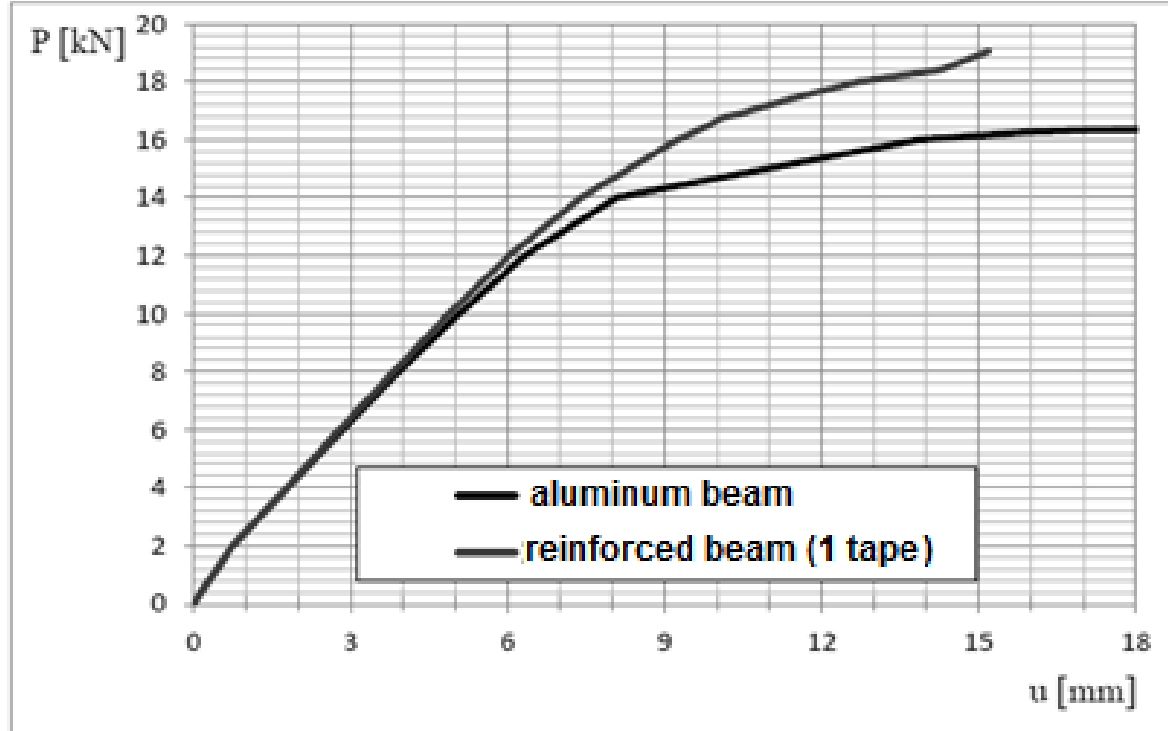

Fig. 2. The force - displacement relationship for a reinforced beam and a non-reinforced beam

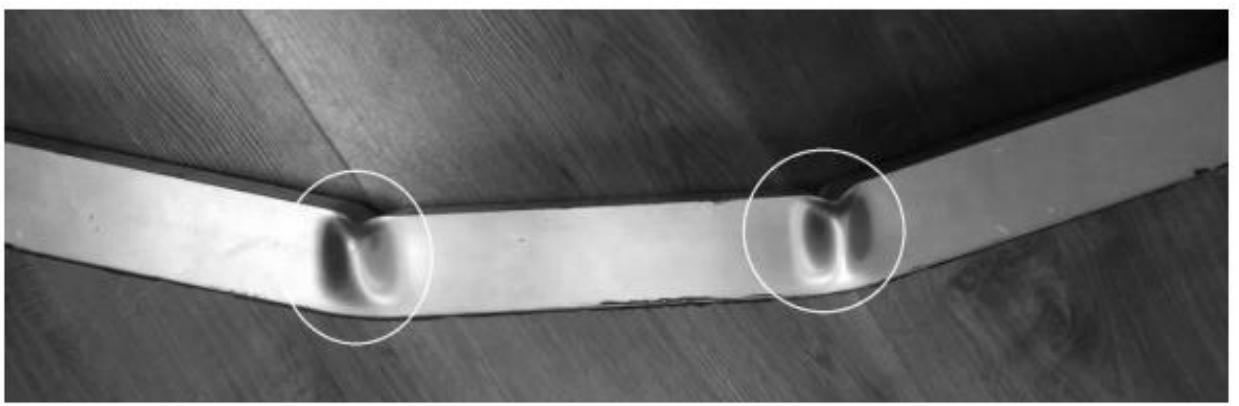

Fig. 3. The deformation of side walls in beams. Four-point bending of the beam (maximum bending force $19 \mathrm{kN}$ )

\section{THE NUMERICAL ANALYSIS}

The analysis with the finite element method is an increasingly common way used in the study of new types of materials. However, it should be remembered that the correctness of the obtained results depends on the selection of an appropriate mathematical and material model. Models analyzed in this work are built using the Ansys software package, which is widely used in scientific and engineering research see the papers (Bielski et al., 2013; Laczek et al., 2001; Chen and Liu, 2014; Gebhardt, 2018; Łaczek, 2011; Łaczek et al., 2013; Moaveni, 2008; Zagrajek et al., 2006; Lee, 2019). For the bent beams, the boundary conditions and the type of load corresponding to the experimental tests were adopted. The aluminum beams and beams reinforced with carbon fiber tapes were the subject of the numerical analysis. The unreinforced beam consists of 5,700 members and 40,090 nodes. The reinforced beam was made up of 6300 and 45063 nodes. Additionally, in places of high stresses or displacements, the mesh was compacted. The performed numerical calculations of the beam bending process enabled the analysis of the deformation state of the directional stresses $\sigma$ (Figs. 4 and 5) at the time when the numerical models obtained the maximum displacements with values corresponding to the results of the experiments. The bending beams and the carbon fiber tapes were modeled as 3D solid objects. The stresses of 
the normally unreinforced beams were compared with the normal stresses of the reinforced beams (Fig. 6).



Fig. 4. Maps of normal stresses in the reinforced beam after bending test, force $P=14 \mathrm{kN}$

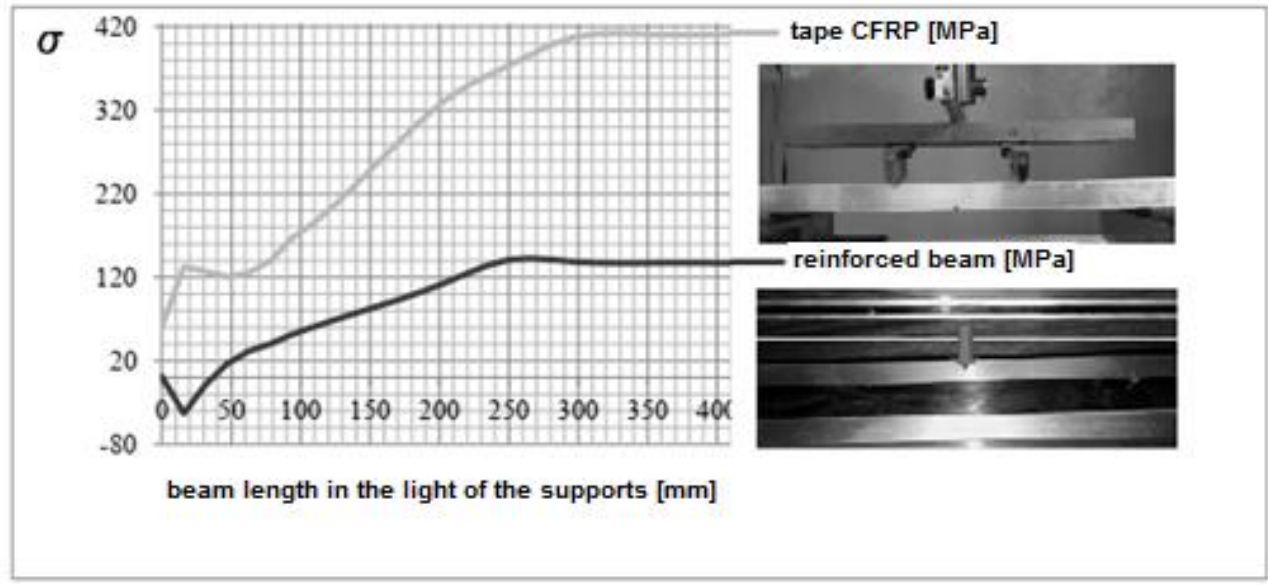

Fig. 5. Diagrams of normal stresses along the reinforced beam

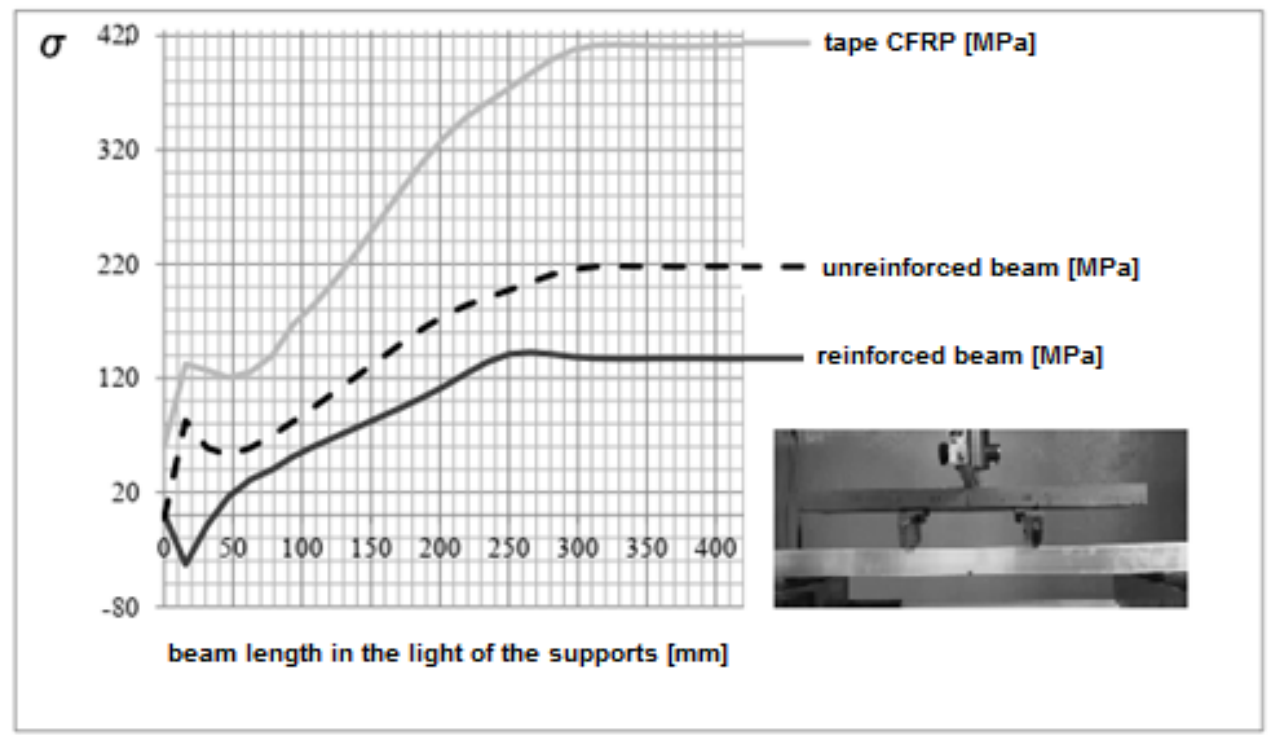

Fig. 6. Diagrams of normal stresses in an unreinforced beam and a reinforced beam 
Taking into account the results of experimental studies and the results of numerical analyzes, the reinforcement of aluminum beams with carbon fiber tapes brings quite big benefits. In terms of elasticity, the conducted analysis showed good compliance of the equilibrium paths with the experimental results. However, it should be remembered that the differences in values may be due to a variety of technical reasons, such as a slight shift of the beams on the supports during the bending process, inaccurate distribution of glue on the beams (samples were prepared by hand), or imperfect alignment of the beam during bending tests, etc.).

\section{SUMMARY}

The experimental tests and numerical analysis have shown that not only the displacement (deflection) is reduced as the bending force increases, but also the stresses in the aluminum beam are significantly reduced by reinforcing with a carbon fiber tape (Fig. 7). The deflection of the reinforced beams, as the force increases from $12 ; 14 ; 16 \mathrm{kN}$ up to the force breaking the beam, decreases in relation to unreinforced beams by about $5 \% ; 8.5 \% ; 33 \%$. The difference in the breaking force of the beam was approximately $67 \%$.

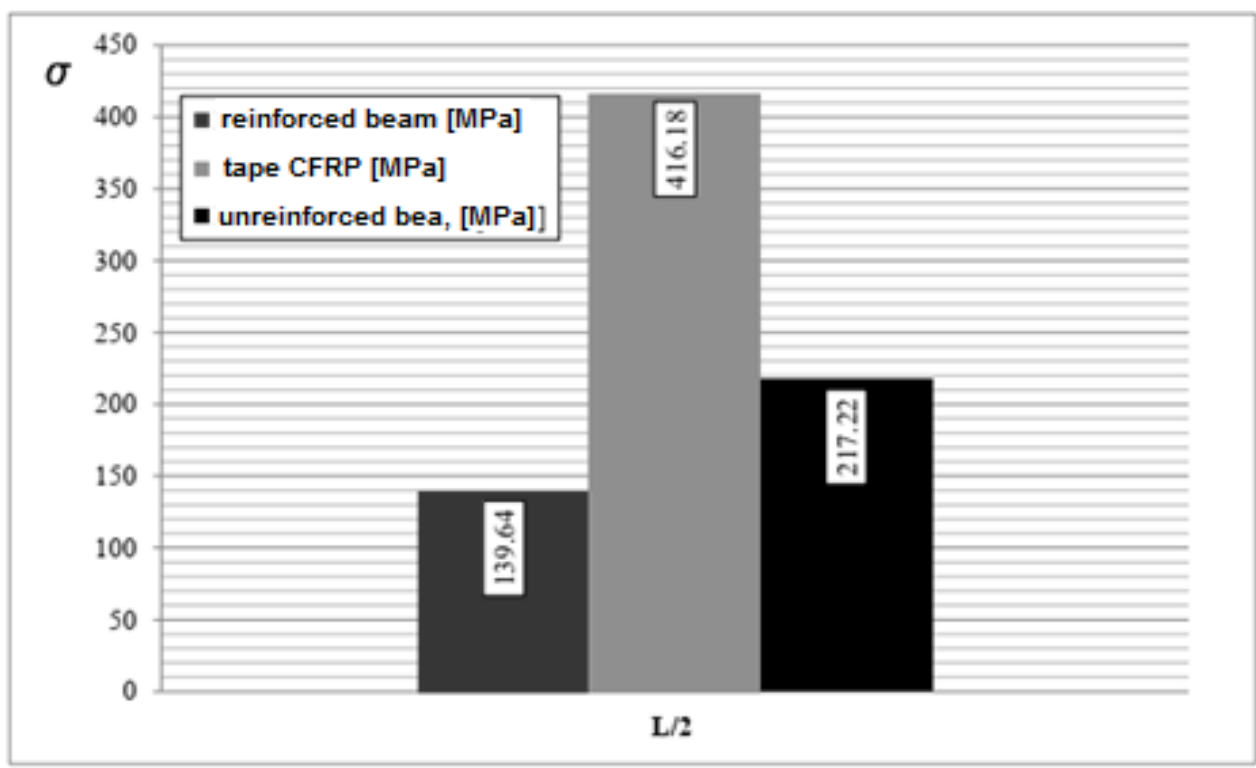

Fig. 7. Diagrams of normal stresses in a beam reinforced with CFRP tape and an unreinforced beam ( $L$ - length in the light of supports $750 \mathrm{~mm}$ )

The conducted experimental research and numerical analysis are confirmed by literature studies on the advantages of using materials such as the aluminum and carbon fiber. These are materials that offer a wide spectrum of use. An additional advantage is their eco-friendliness and the possibility of almost $100 \%$ recycling, which nowadays is one of the factors determining the selection of materials used in engineering structures. The potential for the use of this type of composite in engineering structures is large, starting from the reinforcement of reinforced concrete structures (e.g. bridge spans), wooden and steel structures, motor vehicle components, aircraft components or footbridges, or bicycle paths mounted in a cantilever manner to existing structures. These are just some of the possibilities of using beams reinforced with carbon fiber tapes. An example of application is shown in Figure 8. 




Fig. 8. Examples of the use of aluminum-carbon composite in engineering structures

\section{REFERENCES}

Bednarski, Ł., Sieńko, Howiacki, R.T., 2015. XXX Jubil. Nationwide. Workshops Pr. Design by Konstr, Szczyrk, 25-28.

Bielski, J., 2013. Engineering applications of the system MES, Politechnika Krakowska im. Tadeusza Kościuszki \& Wydawnictwo, Wydawnictwo PK, Kraków.

Chen, X., Liu, Y., 2014. Finite Element Modeling and Simulation with ANSYS Workbench, CRC Press.

Gebhardt, C., 2018. Praxisbuch FEM mit ANSYS Workbench: Einführung in die lineare und nichtlineare Mechanik München, Hanser.

Łaczek, S., 2011. Modeling and analysis of structures in the system MES ANSYS v.11, Kraków, Wydawnictwo Politechniki Krakowskiej.

Łaczek, S., 2013. Examples of structure analysis in the system MES ANSYSWorkbench v.12.1, Wydawnictwo PK, Kraków.

Laczek, S., Szybiński, B., Zieliński, A., 2001. Zesz. Nauk. Mech. Opol., 161-170.

Lee, H.H., 2019. Finite Element Simulations with ANSYS Workbench 2019, Theory, Applications, Case studies, SDC Publications, 612.

Moaveni, S., 2008. Finite Element Analysis: Theory and Application with ANSYS, Pearson Prentice Hall.

Zagrajek, T., Krzesiński, G., Marek, P., 2006. Finite element method in structural mechanics: exercises with the use of the system ANSYS, Oficyna Wydawnicza Politechniki Warszawskiej, Warszawa. 